\title{
Routes to Failure in Rotating MEMS Devices Experiencing Sliding Friction
}

S. L. Miller, G. LaVigne, M. S. Rodgers, J. J. Sniegowski, J. P. Waters, and P. J. McWhorter $\begin{array}{cc}\text { Sandia National Laboratories } & \text { CONF-970968-6 } \\ \text { Mail Stop 1080 } & \text { COE }\end{array}$

P.O. Box 5800

Albuquerque, NM 87185-1080

http://www.mdl.sandia.gov/Micromachine

\begin{abstract}
Gear systems rotating on hubs have been operated to failure using Sandia's microengine as the actuation device. Conventional failure modes such as fatigue induced fracture did not occur, indicating that the devices are mechanically extremely robust. The generic route to failure observed for all rotating devices involves sticking of structures that are in sliding contact. This sticking evidently results from microscopic changes in the sliding surfaces during operation. The rate at which these changes occur is accelerated by excessive applied forces, which originate from non-optimized designs or inappropriate drive voltages. Precursors to failure are observed, enabling further understanding of the microscopic changes that occur in the sliding surfaces that ultimately lead to failure.
\end{abstract}

Keywords: microengine, friction, failure mechanisms, rotating devices, MEMS failure modes

\section{Introduction}

Many technologically significant MEMS devices contain elements that rotate on a hub. For example, positionable mirrors (Fig.1), mechanical locks (Fig. 2) and optical encoders (Fig. 3) are driven by

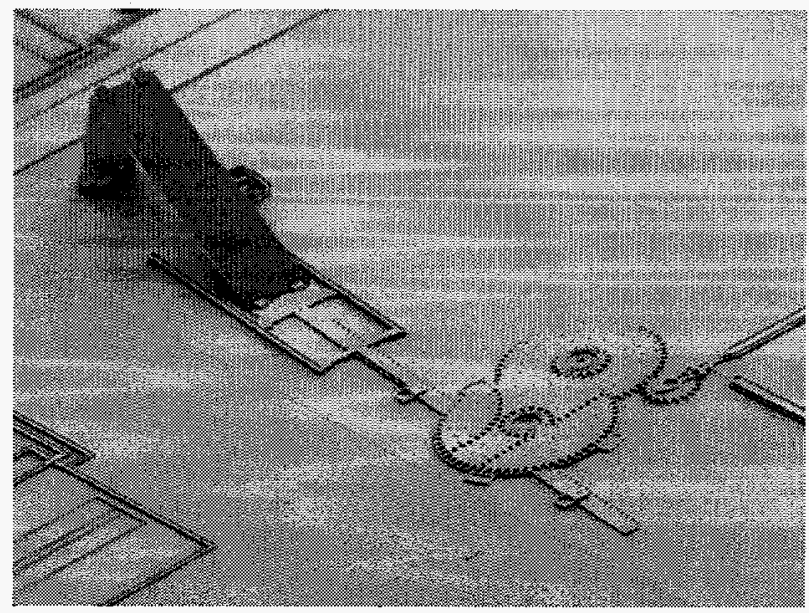

Fig. 1. The microengine pinion gear (right) powers a torque convertor, consisting of a series of multilevel rotating gears. The torque convertor actuates an out-of-plane mirror by pushing a linear rack.

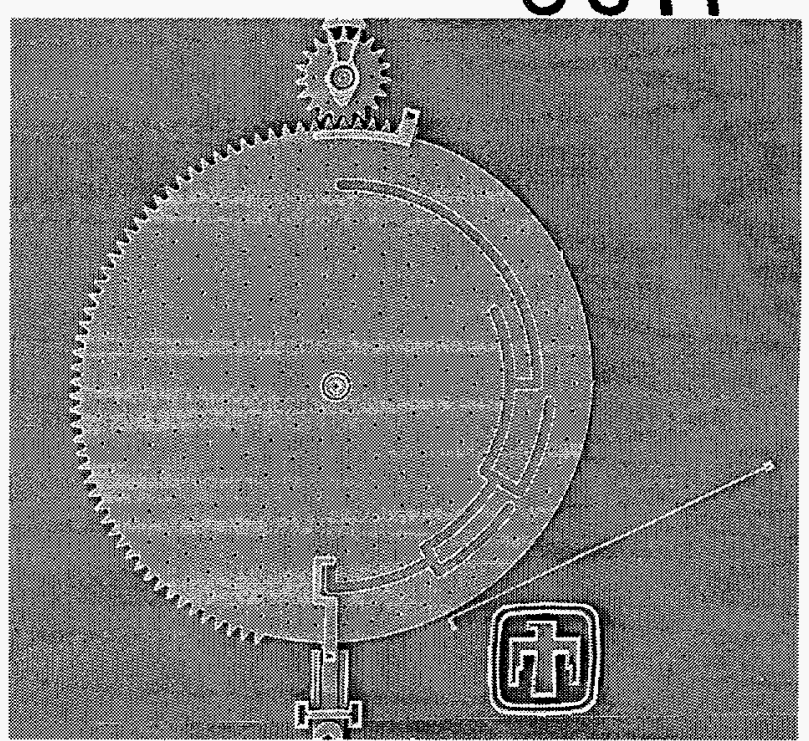

Fig. 2. The microengine pinion gear (top) actuates a mechanical locking device. To actuate the lock, the pin (bottom) must successfully navigate the groved maze in the wheel as the wheel rotates.

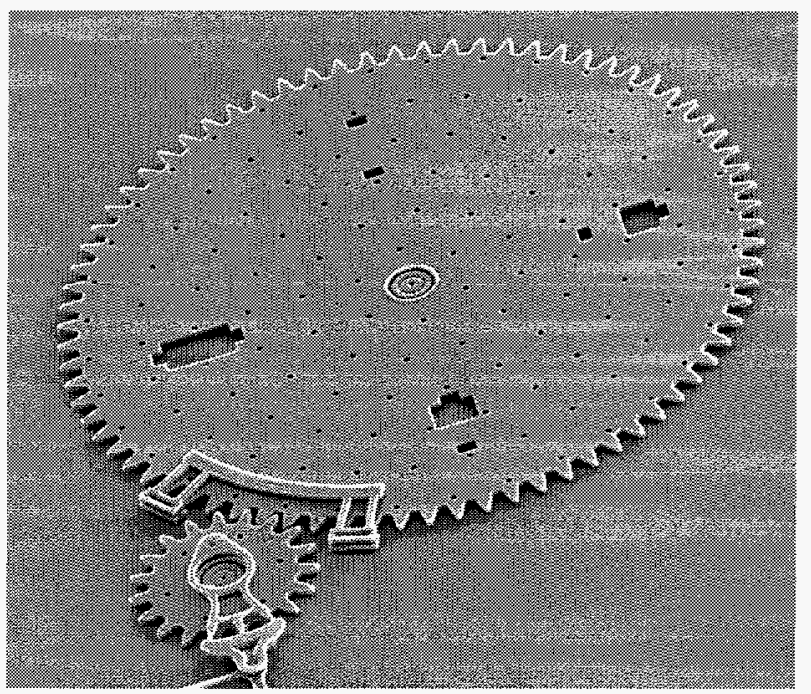

Fig. 3. The microengine pinion gear (bottom left) actuates the rotating optical encoder wheel.

DISTFIBUTION OF THIS DOCUMENT IS UNLIMITED 


\section{DISCLAIMER}

This report was prepared as an account of work sponsored by an agency of the United States Government. Neither the United States Government nor any agency thereof, nor any of their employees, make any warranty, express or implied, or assumes any legal liability or responsibility for the accuracy, completeness, or usefulness of any information, apparatus, product, or process disclosed, or represents that its use would not infringe privately owned rights. Reference herein to any specific commercial product, process, or service by trade name, trademark, manufacturer, or otherwise does not necessarily constitute or imply its endorsement, recommendation, or favoring by the United States Government or any agency thereof. The views and opinions of authors expressed herein do not necessarily state or reflect those of the United States Government or any agency thereof. 


\section{DISCLAMMER}

Portions of this document may be illegible in electronic image produets. Images are produced from the best available original document. 
electrostatically actuated microengines developed at Sandia National Laboratories. ${ }^{1-5}$ The output drive gear of the microengine rotates on a hub, as does the primary lock disk, the optical encoder disk, and the torqueconversion system connecting the engine to the mirror. All these structures experience sliding friction as they rotate (in contrast to harmonic side-drive rotating structures $^{6,7}$ that experience rolling friction). Devices based on these fundamental elements are anticipated to be used in applications where reliability is of utmost importance. Consequently, it is essential that failure mechanisms associated with rotating devices experiencing sliding friction be understood.

To investigate routes to failure, we designed and fabricated devices using Sandia's Ultra-planar Multilevel MEMS Technology (SUMMiT). ${ }^{8}$ This 4-level surface micromachining technology is comprised of 3 levels of mechanical polysilicon and one level of electrical interconnect polysilicon. The resulting devices were operated using model-based drive signals, ${ }^{9,10}$ and the resulting performance measured using a strobebased measurement system. This strobe system, similar to that described by Freeman et al.," ${ }^{11}$ performs automated image acquisition and analysis to provide precise time-dependent position measurements of rotating devices during operation.

In this paper, we describe results of experiments where rotating devices were operated to failure. In addition to identifying the nature and origin of failures, we also describe important ways that these devices do not fail.

\section{Test Vehicle}

The test vehicle used to investigate the failure of rotating devices is the microengine, which is an electrostatically driven actuator that converts linear motion to rotational motion (see Fig. 4). The engine, via the output gear, is capable of delivering torque to a load. The two orthogonal sets of comb drives actuate the output gear through a set of linkages. A pin joint capable of $360^{\circ}$ rotation connects the linkage arms to the gear. The fabrication of this engine has been described elsewhere. ${ }^{1-3}$

To create the proper model-based drive signals with which to operate the engine, several calibration measurements are required. The restoring spring force is given by $\mathrm{F}=-k \mathrm{y}$, where $k$ is the spring constant and $\mathrm{y}$ is the displacement from equilibrium. The electrostatic force provided by the comb drives is given (for the ideal case) by $\mathrm{F}=a \mathrm{~V}^{2}$, where $\mathrm{V}$ is the applied voltage and $a$ is the electrostatic force constant. In equilibrium, $k y=a V^{2}$,

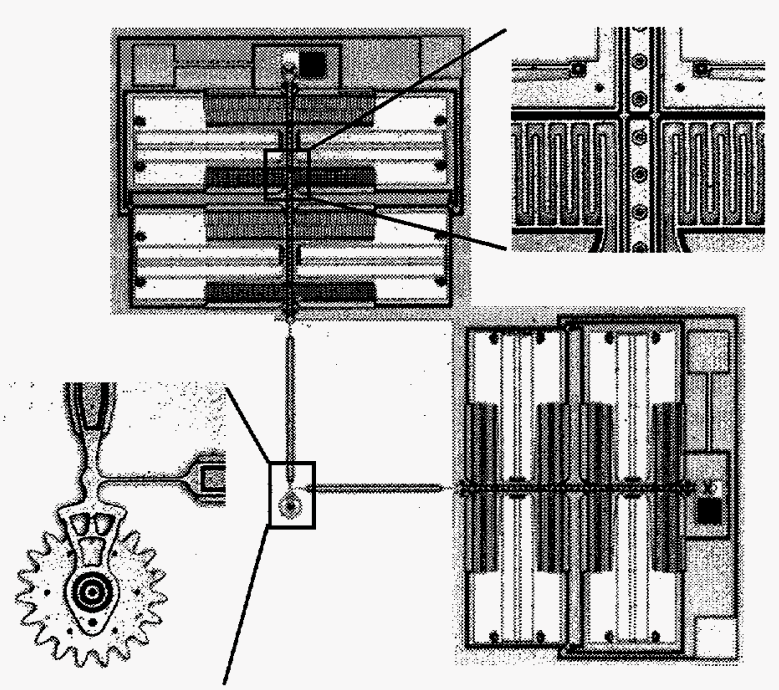

Fig. 4. The microengine converts linear motion from electrostatic actuators to rotational motion. The rotating pinion gear provides torque to actuate other rotating devices as shown in Figs. 1-3.

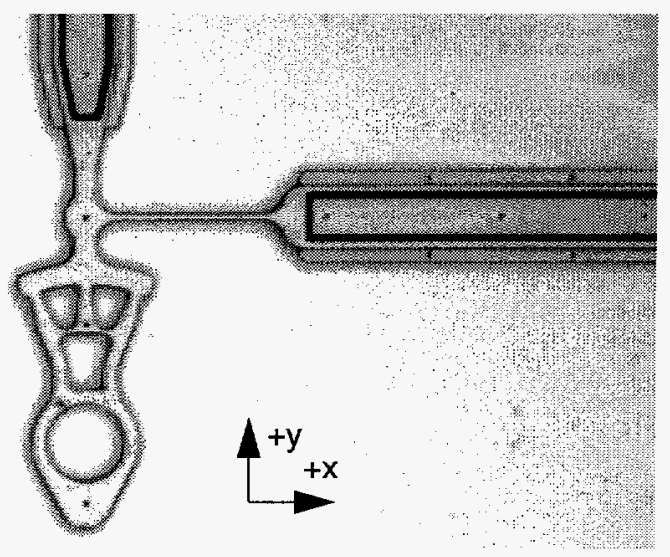

Fig. 5. An engine identical to that shown in Fig. 4, but with the pinion gear omitted, is used for test and calibration purposes.

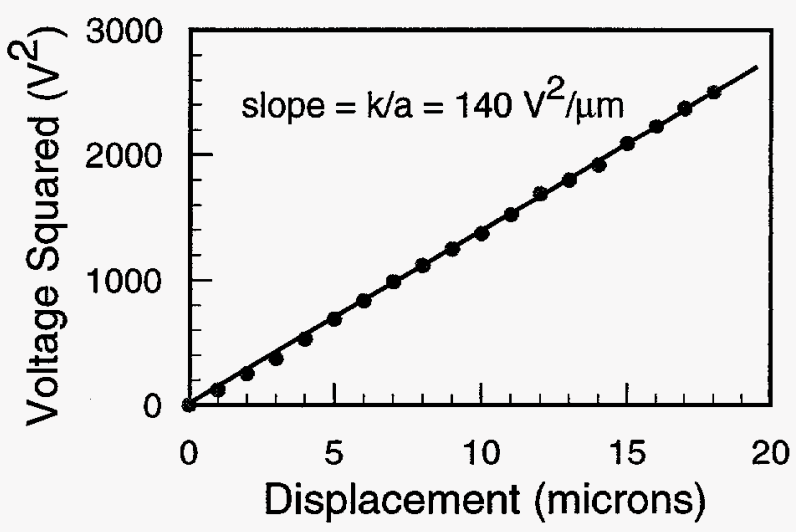

Fig. 6. The experimental displacement of the comb drive as a function of the square of the applied voltage yields the ratio of the electrostatic and spring force constants $k / a$. 
or $\mathrm{V}^{2}=\mathrm{y} k / a$. Using an implementation of the engine where the pinion gear is omitted in the design (Fig. 5), static position vs. voltage measurements were made. As can be seen by the data in Fig. 6, a plot of $V^{2}$ vs. $y$ results in a straight line as theoretically expected. The slope of the line is $k / a=140 \mathrm{~V}^{2} / \mu \mathrm{m}$. The comb drive oriented orthogonally to this one yields similar results.

The final calibration measurement made was the resonant frequency of the comb drives. The resonant frequency of the gearless engine shown in Fig. 5 was experimentally measured to be $1.9 \mathrm{kHz}$. Knowing the resonant frequency and the ratio $K a$ is sufficient to create drive signals appropriate to properly operate the microengine. ${ }^{9}$ Forces associated with air damping have been shown to be negligible compared to other forces relevant to the operation of the engine, and hence are omitted. ${ }^{10}$ As will be discussed later, frictional forces will be found to play a significant role leading to the failure of test devices.

\section{Routes to Failure}

\subsection{Experiment I: Minimal Torque}

A microengine was operated at a speed of 30000 revolutions per minute (rpm) using model-based drive signals. A minimal torque of $\sim 10 \mu \mathrm{Nt}-\mu \mathrm{m}$ was applied to operate the engine; the output gear would not rotate properly with less torque. The position of the output gear was measured during operation using a strobebased measurement system. Images were electronically recorded and digitally analyzed to yield the angular position of the gear as a function of time. The time is known to within $1 \mu \mathrm{s}$, and the gear angle is measured to within 1 degree ( $\sim 0.02$ radians). Measurement errors originate when the operation of the engine is not strictly periodic. Nonperiodicity may result in blurred images; accurate position measurements cannot be made from such images.

When the engine was first started, it operated relatively smoothly, as shown by the data in Fig. 7a. Each data point results from a single digitally acquired image. Deviation from approximately constant angular speed is observed for the time spanning $\sim 0.8 \mathrm{~ms}$ to $\sim 1.3$ $\mathrm{ms}$ (the rotational period is $2 \mathrm{~ms}$ ), where it abruptly speeds up, and then slows down. The short line segment is drawn to highlight this deviation from expected behavior.

The operation of the engine degraded as additional revolutions accrued. Strobe data obtained after the engine accrued approximately 4.2 million revolutions is shown in Fig. 7b. As the engine rotated, it would intermittently stick at the $135^{\circ}$ position for one or more
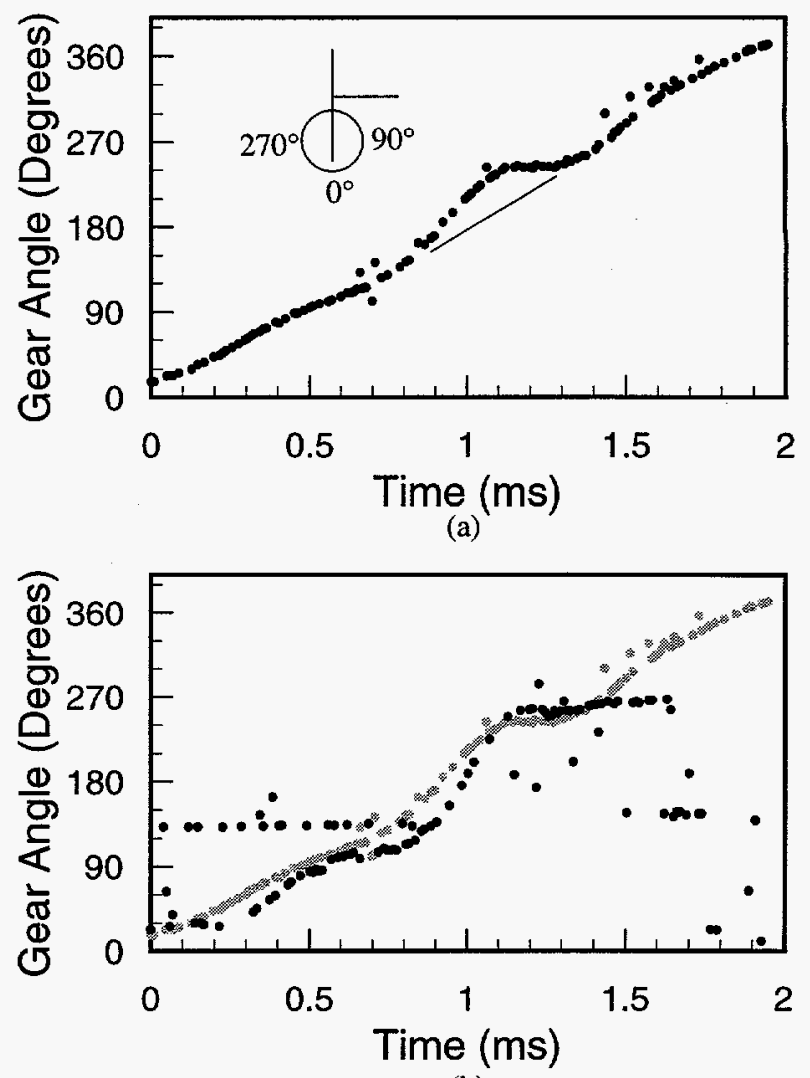

(b)

Fig. 7. Measured gear angle vs. time a) at the beginning of operation and $\mathrm{b}$ ) after 4.2 million revolutions (superimposed on top of the data in (a)). The gear is exhibiting intermittent operation where it sticks at $135^{\circ}$ and $270^{\circ}$. The inset in a) shows the measurement convention for angles.

periods of the drive signal, then spontaneously dislodge and continue rotating. The strobe data for the first half of the drive signal period $(<1 \mathrm{~ms})$ clearly indicate the apparently random transitions between the stuck configuration and the "normally" operating configuration. The multivalued nature of the data simply indicates that on some frames of the strobed image, the gear is stuck, and on other frames it is properly rotating. Additional sticking is observed at the $270^{\circ}$ position. Erratic behavior beyond $1.5 \mathrm{~ms}$ often resulted in blurred images, which do not result in data points. As the engine continued to operate, the frequency of sticking continued to increase, until it finally ceased to rotate.

We note that engines that failed in this manner were typically able to be easily restarted by the application of drive signals that delivered more torque, or by applying a slight nudge with a probe tip. However, engines restarted in this manner would again quickly exhibit degraded operation and would stick again. The ability to restart the devices suggests that the sliding surfaces were somehow temporarily caught on a microscopic asperity that developed during operation. 
It is very clear from data of the type shown in Fig. 7 that the physical change that results in sticking is related to the original anomaly impacting the uniformity of speed of rotation of the gear. The origin of this anomaly was determined by operating the gearless test structure shown in Fig. 5. To verify the accuracy of the model-based drive signals resulting from the calibration parameters measured earlier, the linkage was operated with drive signals intended to produce $17 \mu \mathrm{m}$ and $23 \mu \mathrm{m}$ diameter circular motion. The experimental data in Fig. $8 \mathrm{a}$ show that precisely the expected circular motion results, and with the correct diameters. The gearless engine was then operated with signals intended to produce $34 \mu \mathrm{m}$ diameter circular motion, as is needed to drive the output gear (the radius at which the pin joint connects the linkage to the gear is $17 \mu \mathrm{m}$ ). The resulting motion, shown in Fig. 8b, deviates drastically from the desired $34 \mu \mathrm{m}$ diameter circular motion.

There are several observations to be made regarding the data in Fig. 8. As the linkage rotates counterclockwise, at $\sim 135^{\circ}$ it is abruptly pulled in the ty direction, where further motion in the +y direction is constrained by mechanical stops associated with the comb drives. While still clamped against the stops, the linkage is pulled in the $-x$ direction, where it then clamps in the $-\mathrm{x}$ direction. As the drive signals continue to evolve with time, the - $x$ comb drives unclamp, and the linkage follows a very noisy trajectory past the $0^{\circ}$ position. Motion is as expected from the $90^{\circ}$ position through the $135^{\circ}$ position.

This type of clamping behavior originates from deviations in the ideal force-voltage relationship of the actuating comb drives. Additional experiments show that the relationship demonstrated in Fig. 6 deviates from linearity at a $+y$ displacement of $\sim 30 \mu \mathrm{m}$. In particular, the electrostatic force becomes positiondependent (similar to a parallel plate capacitor) for large displacements due to fringing field effects at the end of the comb fingers. Rather than the comb drive being in stable equilibrium, the fringing field causes the comb drive to be forcibly pulled until it clamps against a mechanical stop. Ideal control of the linkage is achieved except for large comb displacements where this excessive parasitic force occurs. Once parasitic forces perturb the engine drive system (clamping occurs), subsequent motion is perturbed until the system is able to revert back to stable "normal" behavior. This typically occurs when the comb drive voltages drop below critical un-clamping voltages.

There is clear correlation between the motion of the unconstrained (gearless) engine and the sticking points of a degraded engine. Excessive force in the $+y$ direction begins at the $135^{\circ}$ position, as indicated by

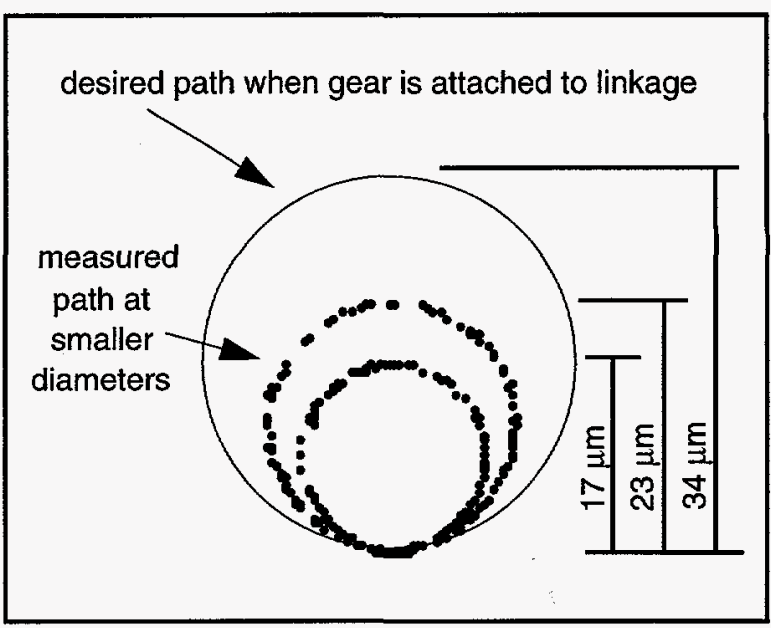

(a)

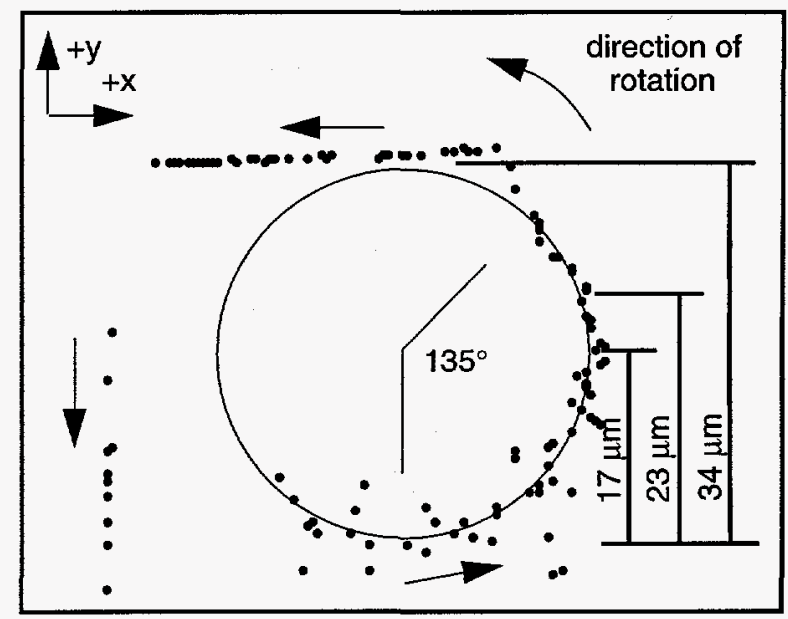

(b)

Fig. 8. a) Gearless test structure operated with model-based drive signals results in desired round trajectories of $17 \mu \mathrm{m}$ and $23 \mu \mathrm{m}$ diameters, as expected. b) When the diameter is extended to $34 \mu \mathrm{m}$ as required for operation with the gear, the trajectory exhibits clamping and other erratic behavior.

Fig. 8b. This excessive force accelerates the counterclockwise rotating gear ahead of its normal constantspeed trajectory, as shown by Fig. 7a. The complex force history of the now-perturbed system also results in the gear coming to a complete stop at $270^{\circ}$ before it recovers back to stable "normal" behavior (Fig. 7a). Primary sticking points of the engine develop at these two critical positions (Fig. $7 \mathrm{~b}$ ). The parasitic forces between rubbing surfaces (e.g. between the comb shuttle and alignment guides, and between the gear and hub) apparently cause some type of physical change in the rubbing surfaces, leading to the observed intermittent sticking, and ultimately to failure. 


\subsection{Experiment II: Excessive Torque}

In the previous discussion, we noted that the application of increased torque to a stuck engine could free it from the stuck configuration. Now we address the question of what happens if an excessively large driving force is applied to operate the engine from the start. To investigate this, an engine was operated with a torque three times larger than that applied in the previous experiment.

The excessive operating force resulted in several parasitic effects. The data in Fig. 9 show the operation of the engine after 2.7 million revolutions. Because the applied force is larger than is required to operate the engine, the engine "self-adjusts" its phase to compensate for the excessive applied force. ${ }^{9,10}$ The phase shift of $+40^{\circ}$ is present even when the engine is first started, as expected. This phase shift results in significantly increased friction between the gear and the hub on which it rotates. ${ }^{9}$ In addition, significant and multiple fluctuations in instantaneous speed are observed in Fig. 9, with a major perturbation occurring at $\sim 180^{\circ}$. The pinion gear also comes to a complete stop each revolution for a full $50 \mu$ s at $386^{\circ}$ (or equivalently, $26^{\circ}$ ). Interestingly, the engine failed shortly after this data set was acquired by firmly lodging at this sticking position.

The fine structure observed in the data in Fig. 9 indicates that the local microscopic properties of the rubbing surfaces vary with position as the gear rotates. The extreme variations in instantaneous angular speed (slope of the data) result from the complex relationship between the applied actuator force and the slip-stick behavior of sliding surfaces. Independent of the actual force history resulting from the drive signal voltages, the evidence suggests that microscopic asperities occurring on the rubbing surfaces are what ultimately lead to increased sticking, and ultimately to failure. Non-ideal drive forces simply have the effect of accelerating the degradation process in localized regions.

\subsection{Ways Devices Do Not Fail}

The operation of hundreds of engines of various designs operating either alone or driving loads such as torque convertors, linear racks, optical shutters, etc. has been observed. We briefly summarize our observations in several categories.

Gear Teeth In no case have meshing gear teeth been observed to break or shear off. The only issue regarding meshing gear teeth is ensuring that they remain properly aligned. Since the gears are very thin $(\sim 2 \mu \mathrm{m})$, and in some cases have large radii (up to $800 \mu \mathrm{m}$ ), very slight stress in the polysilicon can

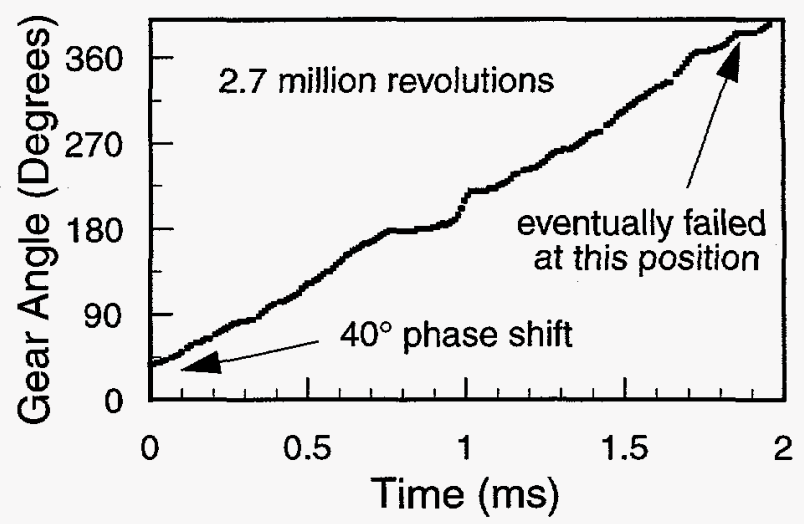

(a)

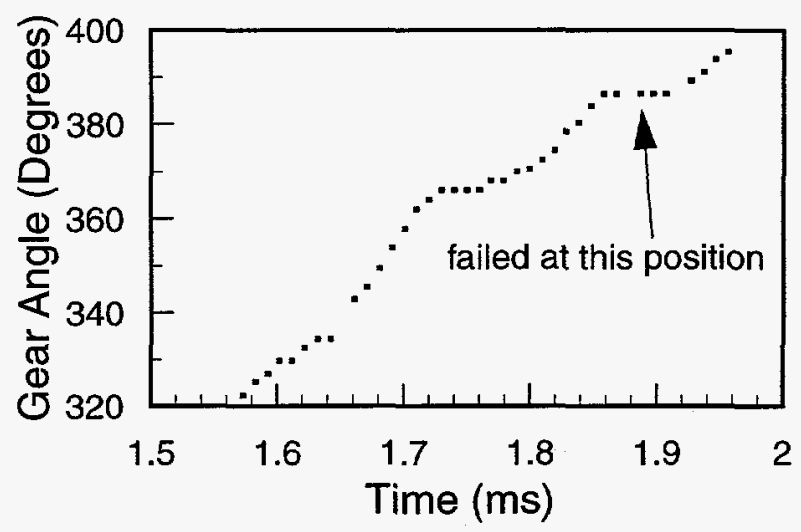

(b)

Fig. 9. a) Increasing the force applied between the gear and hub beyond what is minimally required to operate it results a $40^{\circ}$ phase shift between the gear and drive signal and premature failure due to the development of a sticking point. b) Fine structure (precursors to failure) is observed when the data in (a) are plotted on an expanded scale.

occasionally cause the gear to bow and the teeth to not mesh properly. Even with perfectly planar polysilicon, slight tolerances between the gear and hub can allow misalignment. This alignment issue is effectively mitigated by using clips as shown in Figs. 2 and 3 to hold the gears in proper alignment.

Load Gears In some cases (e.g. when a $1 \mathrm{~mm}$ diameter load gear is slightly bowed), friction between the load gear and alignment clips can impact their operation. Mitigation of this issue has been demonstrated by using reduced stress poly, and by the proper design and placement of alignment clips.

The presence of load gears (such as an optical shutter or torque convertor) typically does not adversely impact the lifetime of the engine driving it. When properly operated with model-based drive signals, individual load gears and gear trains have been operated well in excess of $100000 \mathrm{rpm}$, and individual gear systems have accrued nearly a million start/stop cycles. 
Gear Hubs In no case have gear hubs been observed to mechanically fail by breaking. The only issue associated with hubs pertains to friction and sticking points as discussed earlier.

Pin Joints Pin joints that connect linkages do not typically fail by breaking or shearing. The only case where a pin joint has been observed to fail by shearing was when the polysilicon was severely over-etched in processing splits by surface roughening treatments such as ammonium hydroxide. The pin joint connecting the drive linkage to the engine output gear can occasionally be caused to seize up by the application of excessive forces resulting from improper power up and power down during operation exceeding $200000 \mathrm{rpm}$. This is not an issue for most applications.

Linkages/Flex Joints Linkage arms connecting the comb drives to the pinion gear have not been observed to fail. Flex joints have not been observed to break except when, as a result of processing experiments, they were etched to a width considerably less than a micron.

Comb Drive Support Springs Comb drive support springs have not been observed to wear out or break due to fatigue.

Other Aspects of Comb Drives Comb drive actuators (not connected to a load) have not been observed to wear out or break due to fatigue. Excessive voltages can cause the moving shuttle to come into contact with other surfaces, where it may stick. Obviously, particles can interfere with the proper operation of MEMS devices.

\section{Discussion}

It is evident from these and other experiments that microengine systems fabricated with the SUMMiT process are extremely robust devices. Their operation does not appear to be limited by materials issues such as fracture strength or material fatigue. Gear teeth do not break. Linkage pins do not shear. Hubs do not fracture. Springs do not break. Many engines have accrued hundreds of millions of revolutions before failing, with the record being 3200000000 (3.2 billion) revolutions. (If you could drive to the moon, after two round trips the engine of your car would have accrued $\sim 3.2$ billion revolutions.)

The observed time-dependent routes to failure involve changes that occur in rubbing surfaces. Rotating devices typically exhibit intermittent sticking of rubbing surfaces, with the frequency of sticking increasing until the engine pinion gear no longer exhibits complete rotation, and finally ceases to move at a sticking position. These changes are accelerated by excessive rubbing (frictional) forces, typically originating from the actuation mechanism (comb drive). The rate at which any given engine degrades to the failure point of sticking varies by many orders of magnitude, and depends on the applied forces and apparently the microscopic nature of the rubbing surfaces.

Fortunately, many parasitic forces can be mitigated by design modifications (increase the gap at the end of the comb fingers), and by taking the necessary precautions to apply proper drive signals (use properly calibrated model-based drive signals). However, even with these mitigating precautions, the existence of varying or unknown loads make the open loop operation of rotating microsystems systems challenging. The drive forces will not be precisely balanced with the load, and parasitic frictional forces between rubbing surfaces will result.

In addition to improved device and drive signal designs, there are several additional solutions to the challenge of further increasing the lifetime and reliability of rotating MEMS devices experiencing sliding friction. One solution is to chemically or physically modify the rubbing surfaces to reduce friction and wear (i.e. time-dependent physical changes). Coupling agents have been investigated for this purpose. ${ }^{12}$ Another solution is to implement some type of real-time position measurement capability to enable closed loop control of the system. This may be done using an integrated CMOS/MEMS technology, such as those created at the University of California's Berkeley Sensors and Actuators Center, ${ }^{13}$ at Analog Devices, ${ }^{14}$ and at Sandia National Laboratories. ${ }^{15}$

Precursors to failure are evident from subtleties in the position versus time data obtained early in the life of the devices, as observed in Figs. 7 and 9. Sites where extreme variations in angular speed occur, whether they are due to significant fluctuations in applied forces (Fig. 7) or to spatial fluctuations in the microscopic properties of rubbing surfaces (Fig. 9), are the sites where failure occurs due to eventual sticking. Such sites may be detected early in the life of rotating systems, along with their variation with time as the system progresses to failure. It may be that additional investigation into these precursors will further our understanding of the basic microscopic nature of the failure process, will further the development of quantitative yield and reliability models, and will result in methods to further enhance lifetime.

\section{Summary}

Experiments have been performed on a wide range of rotating surface micromachined devices that experience sliding friction to identify routes to failure. Conventional failure modes such as fatigue induced 
fracture did not occur, indicating that the devices are mechanically extremely robust. The generic route to failure observed for all rotating devices involves sticking of structures that are in sliding contact. This sticking evidently results from microscopic changes in the sliding surfaces. The rate at which these changes occur is accelerated by excessive applied forces, which may originate from non-optimized device designs or inappropriate drive voltages. The existence of measurable precursors to failure should facilitate further understanding and mitigation of the failure process, as well as the development of appropriate reliability models and screening methods.

\section{Acknowledgments}

The authors are grateful to Michael Callahan for funding this work, and the personnel of the Microelectronics Development Laboratory at Sandia National Laboratories for fabricating the devices used in this study.

This work was performed at Sandia National Laboratories and supported by the U. S. Dept. of Energy under contract DE-AC04-94AL85000.

\section{References}

1. J. J. Sniegowski and E. J. Garcia, "SurfaceMicromachined Gear Trains Driven by an On-Chip Electrostatic Microengine", IEEE Electron Device Lett., vol 17, pp. 366-368, 1996.

2. J. J. Sniegowski, S. L. Miller, G. LaVigne, M. S. Rodgers, and P. J. McWhorter, "Monolithic Geared-Mechanisms Driven by a Polysilicon Surface-Micromachined On-chip Electrostatic Engine", Technical Digest of the 1996 Solid State Sensor and Actuator Workshop, Hilton Head Island, SC, June 3-6, 1996, pp. 178-182.

3. J. J. Sniegowski and E. J. Garcia, "Microfabricated actuators and their application to optics", Proc. SPIE Miniaturized Systems with Micro-Optics and Micromechanics, Vol. 2383. San Jose, CA, Feb. 79, 1995, pp. 46-64.

4. Technology of the Year award, Industry Week, A Penton Publication, Vol 244, No. 23, Dec 18, 1995, pp. 30-34.

5. E. J. Garcia and J. J. Sniegowski, "Surface micromachined microengine", Sensors and Actuators A, Vol. 48, (1995) pp. 203-214.

6. M. Mehregany, S. Senturia, and J. Lang, "Friction and wear in microfabricated harmonic side-drive motors", Solid-State Sensor and Actuator Workshop, June 4-7, 1990, Hilton Head Island, South Carolina, pp. 17-22
7. K. Deng, R. Collins, M. Mehregany, and C. Sukenik, "Performance impact of monolayer coating of polysilicon micromotors", J. Electrochem. Soc., Vol 142 (1995), pp. 1278-1285.

8. More technical information regarding the SUMMiT process can be found at the web site http://www.mdl.sandia.gov/Micromachine

9. S. L. Miller, J. J. Sniegowski, G. LaVigne, and P. J. McWhorter, "Friction in Surface Micromachined Microengines", Proc. SPIE Smart Electronics and MEMS Vol. 2722, San Diego, Feb. 28-29, 1996, pp. 197-204.

10. S. L. Miller, J. J. Sniegowski, G. LaVigne, and P. J. McWhorter, "Performance tradeoffs for a surface micromachined microengine", Proc. SPIE Micromachined Devices and Components II, Vol. 2882, Austin, October. 14-15, 1996, pp. 182-191.

11 D. M. Freeman and C. Q. Davis, "Using Video Microscopy to Characterize Micromechanics of Biological and Man-made Micromachines", Technical Digest of the 1996 Solid-State Sensor and Actuator Workshop, Hilton Head Isl., SC, June 3-6, pp. 161-167.

12 U. Srinivasan, M. R. Houston, R. T. Howe and R. Maboudian, "Self-assembled fluorocarbon films for enhanced friction reduction”, Transducers '97, Proc. 1997 Intl. Conf. on Solid-State Sensors \& Actuators, Chicago, June 16-19, 1997, Vol. 2, pp. 1399-1402.

13 W. Yun, R. Howe, and P. Gray, "Surface micromachined, digitally force-balanced accelerometer with integrated CMOS detection circuitry", Proc. of the IEEE Solid-State Sensor and Actuator Wrokshop, p. 126 (1992).

14 W. Kuehnel and S. Sherman, "A surface micromachined silicon accelerometer with on-chip detection circuitry", Sensors and Actuators A, Vol. 45, No. 1, pp. 7-16 (1994).

15 J. H. Smith, S. Montague, J. J. Sniewgowski, J. R. Murray, and P. J. McWhorter, "Embedded micromechanical devices for the monolithic integration of MEMS with CMOS", Intl. Electron Devices Meeting (IEDM) '95, Washington, D.C., Dec. 10-13, 1995, pp. 609-612. 